\title{
Sobre la (múltiple) exclusión femenina: una contribución a nuestra herencia cultural*
}

\author{
Lorena RoMERo GonZÁLEZ \\ Universidad de Castilla-La Mancha \\ Lorena.Romero2@alu.uclm.es \\ ORCID: 0000-0001-7614-0032
}

Sous la direction de

Encarnación Medina Arjona

$\Delta$

\section{MÉMOIRES ET ÉCRITS}

DE FEMMES

La création féminine revisitée

La perspectiva

$$
\text { L'Harmattan }
$$

Desde la segunda mitad del siglo $\mathrm{XX}$, en el contexto de la crítica literaria y artística, se viene examinado «la desigualdad social, cultural y simbólica» (Segarra y Carabí, 2000: 7), especialmente dentro de la ficción literaria, con el fin de derrocar el androcentrismo imperante en las artes y denunciar todo indicio sexista y patriarcal. A raíz de ello, surgen diversas investigaciones de índole política, étnica, religiosa, histórica, etc., que muestran la interdisciplinariedad característica de dicha crítica. En esta línea, el presente volumen compila varias de esas disciplinas haciéndolas girar en torno a un mismo eje temático: la (múltiple) exclusión femenina. Para ello, los participantes, en su mayoría mujeres de trayectoria reconocida en este campo, siguen la pista de tales discriminaciones ha-

ciendo uso y, creando a su vez, un corpus de escritos relativos a mujeres de culturas y épocas diferentes. Todo esto, tal y como adelanta Encarnación Medina Arjona (p. 9), directora de la publicación, hará reflexionar al lector sobre cuestiones como la vulnerabilidad social, los conflictos étnicos o la representación de la alteridad.

El libro aquí reseñado propone un itinerario crítico que se abre con cuatro trabajos bien diferenciados en los que se ahonda en materia étnica y religiosa. En

\footnotetext{
* Acerca del volumen dirigido por Encarnación Medina Arjona, Mémoires et écrits de femmes. La création féminine revisitée (París, L'Harmattan, Colección "La perspectiva textual", 2019, 322 pp. ISBN: 978-2-343-15934-8).
} 
primer lugar, Marta Segarra hace uso del componente irónico de la expresión "dormir à la belle étoile" para enseñar la doble, incluso triple, discriminación dirigida a las mujeres romaníes. En el caso de M. Carme Figuerola, se hace una incursión en la cultura musulmana a partir de la palabra escrita de tres mujeres que reflejan cómo la alteración de la idiosincrasia viene motivada por las normas sociales y familiares patriarcales. Vicente Enrique Montes presenta la novela Celles qui attendent de Fatou Diome quien, aun manteniendo la tradición literaria senegalesa, critica duramente el trato que recibe la mujer en ese país. En último lugar, Bernadette Rey Mimoso-Ruiz da a conocer Cette fille-là de la autora argelina Maïssa Bey y, en particular, los mensajes integrados de denuncia contra la misoginia de su país.

Dejando atrás ese hilo conductor, conocemos la iniciativa de Béatrice Didier que apuesta por elaborar un diccionario "de creadoras" con el fin de luchar contra la exclusión de la mujer y derribar así barreras y prejuicios. Mirando hacia atrás en el tiempo cabe destacar, por un lado, el trabajo de Brígida M. Pastor, quien habla del doble reto al que se enfrentaban las escritoras decimonónicas para poder autentificar su voz como mujer: qué y cómo escribir; por otro, María Victoria Rodríguez Navarro se adentra en la lírica renacentista y ensalza la figura de Louise Labé, quien se alejó del prototipo de "mujer-objeto" para anteponer a la "mujer-sujeto" en su discurso.

A continuación, se ponen de manifiesto las experiencias traumáticas, a la par que reveladoras, vividas por varias mujeres en algunos de los tiempos más convulsos de la historia universal. Entre ellas, Nuria Añó se ocupa de la actriz y guionista judía de Hollywood Salka Viertel y de su actitud frente al nazismo; Marie France Borot presenta a una memorialista y testigo de las grandes atrocidades sucedidas en los campos de concentración de Auschwitz y Ravensbrük; Ana Moreno Soriano e Isabel Segura Moreno analizan las Memorias de Melancolía de María Teresa León, centradas en los tiempos de exilio; y, por último, Cristina Solé Castells profundiza en la necesidad de Clara Malraux por conocerse y definirse.

A medida que avanzamos en la lectura, encontramos estudios como el de Claude Benoit Morinière dedicado a la escritora Griséldis Réal; en concreto, a dos de sus obras que muestran un claro compromiso con la causa y defensa de los derechos de las prostitutas. Asimismo, Azahara Galán Sánchez indaga en la confusión de género con la que juega Rachilde ${ }^{1}$ en sus relatos. Vicenta Garrido Carrasco hace uso de los cuentos de Madame d'Aulnoy y de Perrault con el objetivo de dar a conocer la exclusión de la mujer en la sociedad patriarcal, haciendo hincapié en el concepto de "belleza" y su estrecha relación con el triunfo o el rechazo. En último lugar, Luisa Montes Villar se inclina por la temática de la identidad y del cuerpo femenino en las obras de Adelaida Blázquez.

En el ámbito iberoamericano y, más concretamente, brasileño, Hortensia Caro Sánchez nos transporta a los ritos y cultos de la memoria popular de Brasil a través de la figura femenina estereotipada de Pombagira. Ana María Colling se fundamenta en textos legislativos brasileños para reflejar la larga historia de vio-

\footnotetext{
${ }^{1}$ Pseudónimo masculino de la escritora Marguerite Eymery.
} 
lencia hacia el sexo femenino. Por su parte, Losandro Antonio Tedeschi basa su estudio en la idea de "género" junto con la de interculturalidad, tomando como puntos de referencia principales las regiones fronterizas entre Brasil, Paraguay y Bolivia.

La discriminación múltiple se ve reflejada, sobre todo, en los estudios de María Luisa Guerrero Alonso, quien presenta la historia de lucha por la integración social femenina de Olympe de Gouges, y de José Luis Miguel Jover que, desde una perspectiva más amplia, analiza los factores excluyentes referidos a las mujeres de la historia antigua griega.

Por su parte, Lydia de Haro Fernández retrata la condición femenina en el marco de la Francia rural del siglo XIX a través del personaje de Victoire la Rouge de Georges de Peyrebrune ${ }^{2}$. Myriam Mallart y Àngels Santa demuestran, en sus trabajos respectivos, que ni las élites sociales ni la alta sociedad viven al margen de tales discriminaciones, presentando los casos de Catherine Pozzi (Mallart) y de Marie-Julie de Cavaignac (Santa). Finalmente, resaltamos la contribución de Ángeles Sirvent Ramos, que rinde homenaje a las primeras escritoras de la literatura subsahariana, quienes contribuyeron, al igual que los hombres, a la formación del patrimonio cultural de esta parte de África.

En definitiva, el volumen constituye una (re)examinación de escritos sobre nuestra realidad social, histórica y, sobre todo, literaria desde la perspectiva de género con el fin de mostrar la exclusión social femenina mencionada y poner en tela de juicio la herencia cultural que han dejado sociedades de diversas comunidades del mundo, en especial, el francófono. Para su consecución, se ha optado por una amplia pluralidad de enfoques: la combinación de escritoras de siglos pasados (Louise Labé, Olympe de Gouges o Madame d'Aulnoy) con otras de la actualidad (Alice Ferney, Maïssa Bey o Fatou Diome); lo francés y lo francófono ("l'Afrique Noire"); mujeres camufladas de hombres (Rachilde, Peyrebrune); mujeres (mal) conocidas a la sombra de hombres relevantes (Salka Viertel, Claire Malraux, María Teresa León); minorías sociales (judías, romaníes), etc. Si bien es cierto que abundan desde hace unos años los estudios vinculados a esta línea de investigación, como los de Christine Planté (2003) o de Michele de Sadeleer (2016), esta obra colectiva destaca por su riqueza cultural y disciplinar. Como resultado, el proyecto puede proporcionar al lector (más o menos especializado) una perspectiva realmente amplia que abarca desde la sociología de género hasta la crítica literaria.

Dicho esto, en el proceso de lectura hemos podido observar el silencio, la animalización, el castigo o la resignación como otros tantos rasgos discriminatorios que han acompañado históricamente al género femenino. Así pues, todos los enfoques aquí mostrados convergen en un único proyecto y con un mismo objetivo: seguir la pista a algunas de tantas mujeres que en su momento fueron acalladas pero que, gracias a estudios como el presente, no serán olvidadas.

\footnotetext{
${ }^{2}$ Pseudónimo masculino de la escritora Mathilde de Peyrebrune.
} 


\section{REFERENCIAS BIBLIOGRÁFICAS}

PlANTÉ, Christine (2003): «La place des femmes dans l'histoire littéraire : annexe, ou point de départ d'une relecture critique ?». Revue d'histoire littéraire de la France, 103:3, 655-668.

SADELEER, Michele de (2016): La construction de l'identité féminine dans les textes littéraires des écrivaines québecoises. Tesis doctoral dirigida por Ángeles Sirvent Ramos. Alicante, Instituto Universitario de Investigación en Estudios de Género de la Universidad de Alicante.

SEgARrA, Marta \& Àngels CARABí (2000): Feminismo y crítica literaria. Barcelona, Icaria Editorial. 